\title{
Progress on the national echinococcosis control programme in China: analysis of humans and dogs population intervention during 2004-2014
}

Qing $Y u^{1,2,3,4,5}$, Ning Xiao $2,3,4,5,6$, Shuai Han ${ }^{1,2,3,4,5}$, Tian Tian $2,3,4,5,6$ and Xiao-Nong Zhou $2,3,4,5,6^{*}$

\begin{abstract}
Background: A national control program for echinococcosis has been in effect since 2005 in China. This program has applied a comprehensive strategy, and good control results have been achieved. Human echinococcosis prevalence rate decrease from $1.08 \%$ in 2004 to $0.24 \%$ in 2012. The objective of this study is focusing on assessment of the programme with two indices, including patient treatment and registered dogs deworming, in endemic areas of echincoccosis control over the period of 10 years (2004-2014) in China.
\end{abstract}

Methods: We established the database including demography at county and township levels with coverage for ten provinces and autonomous regions of China in this study. We using methods of epidemiological descriptive, instead the expectation-maximization for missing value filling for grouping available patients into those subjected to surgery and those receiving drug treatment after population screening and the dogs population after registered by deworming. We performed Microsoft Excel software and SPSS software on the results as percentages with the corresponding $95 \%$ confidence intervals $(95 \% \mathrm{Cls})$. We also statistically analyzed the economics data on patient treatment and dogs deworming after the corresponding discount with annual bank interest rates (USD $1=$ CNY 6.5, bank discount average changes of 2.3-3.3\%).

Results: During 2004-2014, the grant total average rate of surgical patient (after surgical operation) treatment had increased with $32.4 \%$ and with $81.3 \%$ for medical treatment with albendazole. Meanwhile, it increased by $58.6 \%$ for the deworming of registered dog since 2007. The accumulated costs amounted to USD 27.03 million after discount for patients and registered dog treatment, which is $1 / 4$ of the total accumulated financial inputs (USD 110.67 million from the Chinese Government). Since the implementation of the national program, it has increased 57 times with respect to the annual financial inputs (costs) and 368 times with respect to all accumulated financial inputs (costs).

Conclusions: This study showed that in endemic areas, patient diagnosis and management, dog management and treatment over this period helped reduce the parasite load to control the disease. More attention should be paid to controlling wild canines during the ongoing program period and sustainable follow-up evaluations are crucial for success and continued implementation of the national program.

Keywords: Control progamme, Effectiveness, Echinococcosis, China

\footnotetext{
* Correspondence: zhouxn1@chinacdc.cn

${ }^{2}$ Chinese Center for Tropical Diseases Research, Shanghai 200025, China

${ }^{3}$ WHO Collaborating Centre for Tropical Diseases, Shanghai 200025, China

Full list of author information is available at the end of the article
}

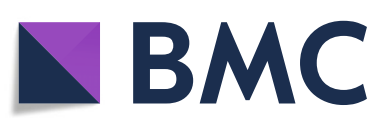

( ) The Author(s). 2020 Open Access This article is licensed under a Creative Commons Attribution 4.0 International License, which permits use, sharing, adaptation, distribution and reproduction in any medium or format, as long as you give appropriate credit to the original author(s) and the source, provide a link to the Creative Commons licence, and indicate if changes were made. The images or other third party material in this article are included in the article's Creative Commons licence, unless indicated otherwise in a credit line to the material. If material is not included in the article's Creative Commons licence and your intended use is not permitted by statutory regulation or exceeds the permitted use, you will need to obtain permission directly from the copyright holder. To view a copy of this licence, visit http://creativecommons.org/licenses/by/4.0/. The Creative Commons Public Domain Dedication waiver (http://creativecommons.org/publicdomain/zero/1.0/) applies to the data made available in this article, unless otherwise stated in a credit line to the data. 


\section{Background}

Echinococcosis (hydatid disease) is one of the 17 neglected tropical diseases recognized by the World Health Organization (WHO) and its continued spread is a severe public health concern [1]. Echinococcosis is mainly endemic in areas of central, eastern and western Asia, South America, Oceania and southern, northern and eastern Africa. Infection in humans/livestock/small mammals is caused by the larval stage of the parasite. Canines (i.e. dogs, foxes, and wolves) are the definitive hosts and play a key role in the transmission and dissemination of the adult stage of this tapeworms belonging to genus Echinococcus. The two most important zoonotic species, E. granulosus (the causative agent of cystic echinococcosis - CE) and E. multilocularis (the causative agent of alveolar echinococcosis - AE), are a serious threat to over 1 million people and responsible for over USD 3 billion in expenses every year. Expressed in global disability-adjusted life years (DALYs), losses of 0.3-1 million DALYs for CE and 0.65 million DALYs for $\mathrm{AE}$, respectively, have been reported [2-5].

China has a high prevalence of human $\mathrm{CE}$ and one of the highest prevalence levels of human $\mathrm{AE}$, accounting for $40 \%$ of global DALYs lost worldwide [4, 6-8]. Both diseases are widely endemic in the pastoral and farmingpastoral regions of Inner Mongolia, Sichuan, Yunnan, Tibet, Shaanxi, Gansu, Qinghai, Ningxia, and Xinjiang provinces/autonomous regions covering 350 counties, with 120000 people infected and 50 million people estimated at risk according to the national prevalence survey of echinococcosis initiated by the National Ministry of Health in 2012 [9]. Notably, canine infectious sources in wild environments in the above endemic areas play important roles in the transmission dynamics of both diseases [10-13].

A national program for echinococcosis control with comprehensive approaches was launched in 2005, that led by National Ministry of Health was implemented in sectoral collaboration with 13 other ministries, e.g., the Ministry of Agriculture and the Ministry of Water Resources. The activities consisted of health education, sanitation improving, ultrasound screening of the human population, surgical interventions and treatment with albendazole, including management and deworming of the dog population ( 8 times above per year). This program has developed well, particularly thanks to the national control action plan (2010-2015) implemented by the Chinese Government, as evidenced by the human echinococcosis prevalence rate, which has shown a remarkable decrease from $1.08 \%$ in 2004 to $0.24 \%$ in 2012 $[9,14-16]$. The key measures were monthly praziquantel oral treatment (reported to have $99.9 \%$ efficacy by WHO) of registered dogs in addition to large-scale human surgical interventions and oral treatment in the endemic regions [17]. Clearly, control of $\mathrm{CE}$ and $\mathrm{AE}$ will have important economic consequences. An evaluation of the outlays of the human intervention and deworming of the dog population is essential and should be part of any program aimed at the control of parasitic zoonoses [18]. The objective of this study was to assess progress and outlays for the national echinococcosis control program at the central government level over a 10 -year period up to 2014. This assessment includes a comprehensive, epidemiological description and economics analysis with estimates for human and dog interventions in the endemic areas of China for the period 2004-2014.

\section{Methods}

\section{Study area}

Based on the National Control Plan on the Prevention and Control of Key Parasitic Diseases (2006-2015) [15], the study was conducted in the pastoral and farmingpastoral regions of project counties in ten provinces and autonomous regions (Inner Mongolia, Sichuan, Yunnan, Tibet, Shaanxi, Gansu, Qinhai, Ningxia, Xinjiang and the Xinjiang Production and Construction Corps) where the echinococcosis control measures were implemented and supported by budgeted annual financial requirements by the Chinese Central Government covering the period 2004-2014 (Figs. 1 and 2).

\section{Data collection}

All data were obtained in the form of echinococcosis control statistics from the disease-endemic areas approved by the National Ministry of Health for each year of the 10-year period. Data involving patient privacy were not involved. Based on the collected information, a database was established that included demography at county and township levels, grouping available patients into those subjected to surgery and those receiving drug treatment after population screening. Information was given regarding the diagnosis $(\mathrm{CE}, \mathrm{AE}$, co-infection or unclassified) and the number of registered dogs and that of those dewormed. The situation with respect to humans and dogs were described using epidemiological descriptive analyses and the direct costs calculated after discount.

\section{Data analysis}

\section{Statistical analysis on human and dog intervention}

Epidemiological descriptive for human and dogs population were performed using Microsoft Excel software, version 2016 (Microsoft Office, CA, USA) and SPSS software version 22 (SPSS Institute, Chicago, IL, USA). The maps for the distribution of human echinococcosis ( $\mathrm{CE}$ and $\mathrm{AE}$ ) prevalence in 2014 were generated using ArcGIS software, version 10 (ESRI, Redlands, CA, USA). 


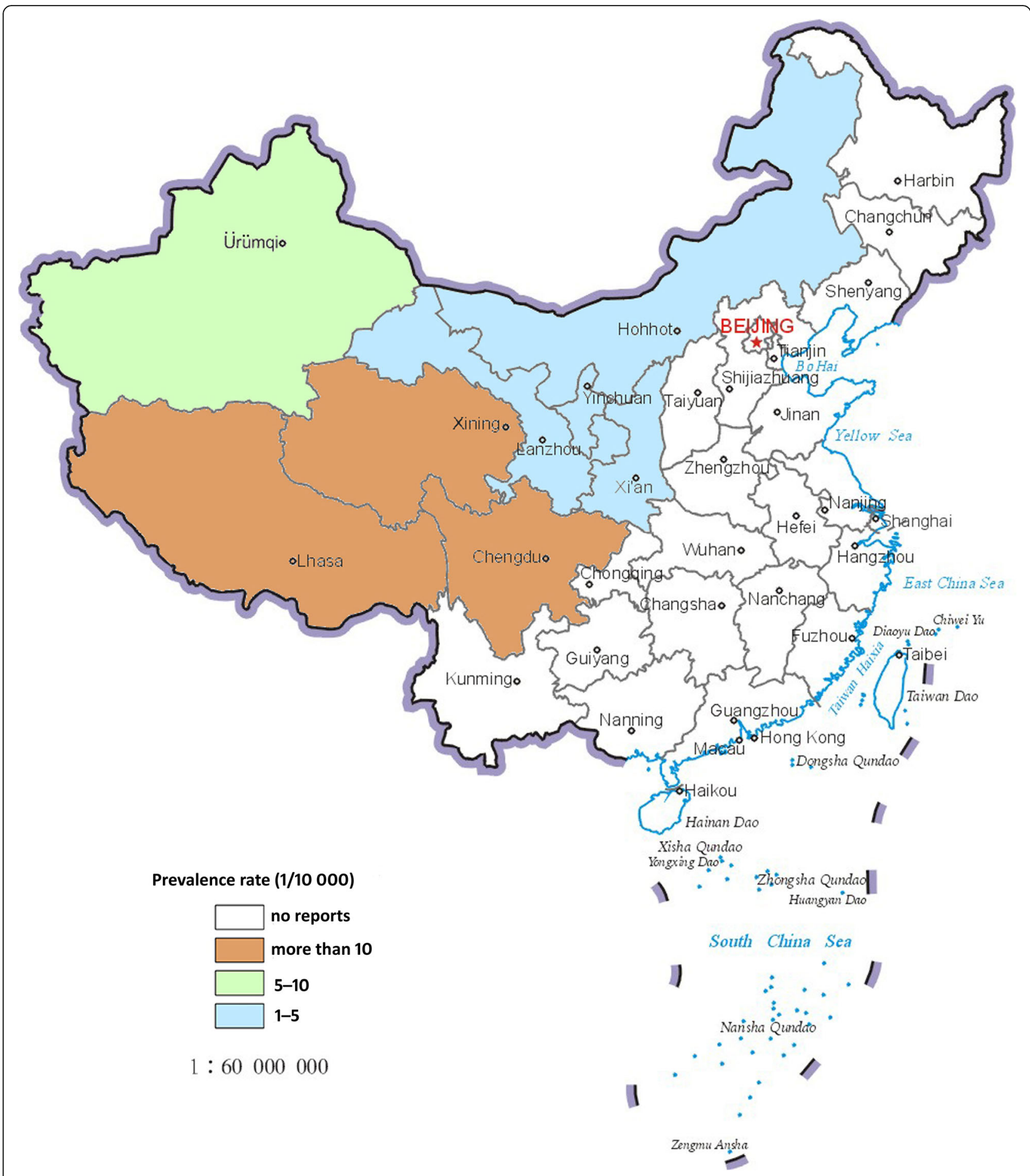

Fig. 1 Geographic distribution of human cases of cystic echinococcosis (CE) reported by the Chinese system for infectious diseases in 2014

The results are shown as percentages with the corresponding 95\% confidence intervals (95\% CIs). The annual numbers of dewormed dogs were not directly acquired for the period 2012-2014 due to a change in the statistical criterion adjustment in these years; instead the expectation-maximization
(EM) method for missing value filling (https://en.wikipedia. org/wiki/Expectatio-maximization_algorithm) was used to estimate the number of dewormed dogs statistically with reference to the annual total of the registered dog variable and the human prevalence rate for 2004-2011. 


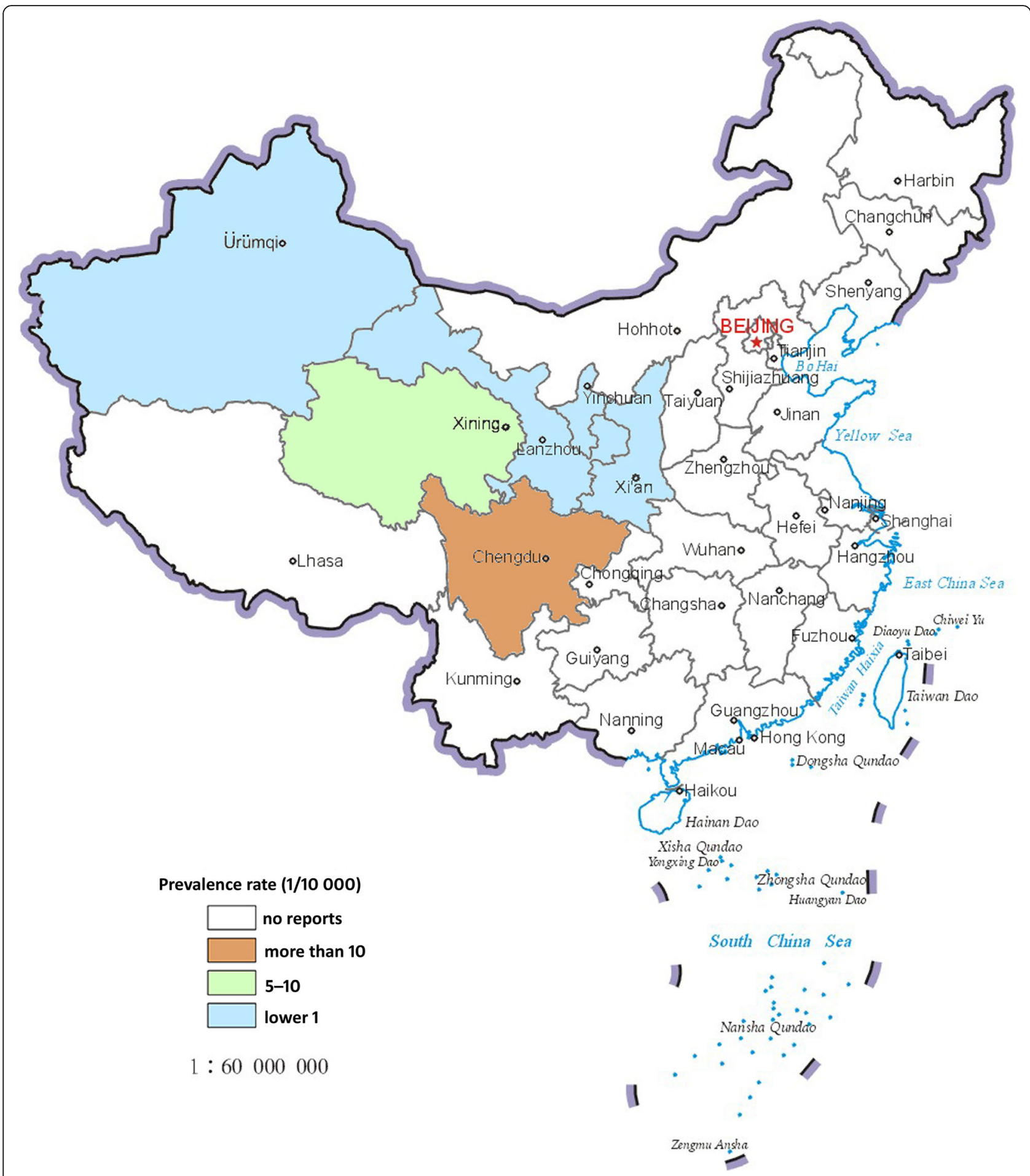

Fig. 2 Geographic distribution of human cases of alveolar echinococcosis (AE) reported by the Chinese system for infectious diseases in 2014

\section{Statistical analysis on the outlays}

The annual financial outlays for the control activities were allocated at the province and county level by the Chinese Central Government. The methods of economics deviations and proportion comparison were used for the outlays of patients' treatment and dogs deworming statistics and analyzed. The outlays after discount of each documented surgical and treatment patient was in accordance with the national available direct financial inputs approved by the State Ministry of Finance as 
follows (using the exchange rate of USD $1=$ CNY 6.5): the annual financial inputs calculated with bank discount average changes of 2.3-3.3\%: USD 1230 per surgical case; and USD 1.20 per treatment case at the beginning of 2006 [19]. Additionally, six formulas were expressed as follows for the estimated gap analysis between estimated and actual needs on available patients and registered dogs population calculated and analysis.

1) The annual gap for treatment of patients $(\mathrm{A} 1)=$ the annual number of available patients in need of treatment - the actual annual cost for patient treatment based on cost, actual number of patients and treatment (CAT);

2) The annual gap for dog deworming (A2) = the annual number of registered dogs needing deworming - the cost for annual actual dogs deworming based on cost, actual number of dogs and deworming (CAD);

3) The accumulated gap for patient treatment (A3)= The accumulated number of available patients in need of treatment - the actual accumulated cost for patient treatment based on cost, actual number of accumulated patients and treatment (CAAT);

4) The accumulated gap for dog deworming (A4) = the accumulated number of registered dogs needing deworming) - the actual accumulated cost for dog deworming based on cost, actual number of accumulated dogs and deworming (CADD);

5) Grand annual proportion $=\mathrm{A} 1+\mathrm{A} 3 / \mathrm{CAT}+\mathrm{CAD}$; and

6) Grand accumulated proportion $=\mathrm{A} 2+\mathrm{A} 4 /$ CAAT+CADD.

\section{Ethical statement}

The database is original from National Institute of Parasitic Diseases, China CDC that authorized by National Ministry of Health, China.

\section{Results}

\section{Humans intervention}

During the period 2004-2014, the total number of human echinococcosis cases reported in the endemic areas ranged from 1749 to 31507 among 56.7-79.7 million inhabitants at the county level and 19.3-39.1 million inhabitants at the township level. The grand total included individuals identified by annual mass screening (4.8\% [959/20 168]-18.2\% [318/1749]), the number of patients subjected to surgical intervention (38.1\% [938/ 2461]-91.1\% [12572/24 733]) and patients receiving treatment (53.4\% [1313/2461]-98.0\% [20 196/20 624]). The statistical analysis of the patients showed that although the average rate of surgical operations for 2005-2006, i.e. before the implementation of the national control program, was greater than $10 \%$, the rate declined to $5.7 \%$ in 2007 (95\% CI: $5.0-6.9 \%)$ and remained stable until 2014. The average coverage rate (the grant total average rate) of patients under treatment was $69.4 \%$ (95\% CI: $56.8-82.0 \%$ ) in 2007, while the total coverage rate was $76.7 \%$ (95\% CI: $67.5-87.9 \%)$ in 2014; these rates were stable over the whole study period (Table 1).

Additionally, the number of surgical cases changed from 318 (18.2\%) to 2379 (7.55\%) from 2004 to 2014 (Table 1). A total of 121 patients (with co-infections) underwent surgical operations since 2010, and 513 unclassified cases were recorded since 2008. Moreover, 134249 person-hours (the total time used for surgical treatment and drug treatment) were reported since 2010, including 74145 person-hours for CE, 28833 for $\mathrm{AE}$ and 1802 for co-infection. However, 29469 personhours remained unclassified since 2008, particularly within the 2-year period 2011-2012 when the accumulated total person-hours were greater than 10000 . During these years, the mean prevalence for surgical patients after diagnosis as the patients at the county level (the project county) were $2.7(\mathrm{CE}), 0.1(\mathrm{AE}), 0.02$ (co-infection) and 0.1 (unclassified) per 100000 persons, respectively, while those at the township level were 2.9, $0.2,0.04$ and 0.13 per 100000 persons, respectively. It should be noted that some patients were not suitable for surgery. The person-hours for the patients having received treatment were $10.2(\mathrm{CE}), 3.9(\mathrm{AE}), 0.3$ (co-infection) and 4.4 (unclassified) at the county level, respectively, while the corresponding figures at the township level were 21.8, 8.5, 0.6 and 7.4, respectively (Table 2, Figs. 3, 4, 5 and 6).

\section{Registered dogs intervention}

Over the 10-year period from 2004 to 2014, the number of registered dogs tended to increase, i.e. reaching 28 times the previous annual number with a medium value of 115.0 (95\% CI: 83.779-226.0), while the annual number of registered dogs already subjected to deworming increased 49 times with a medium value of 46.8 (95\% CI: 35.9-151.1), respectively. In addition, the deworming coverage rate increased $73 \%$ in 2014 in comparison to 2005 with dogs being dewormed 6, 10 and 12 times per year based on an estimation according to the number of registered dogs during the period of 2012-2014 (Table 3). Because disease surveillance was not performed in the endemic regions due to the uneven development of disease control, the actual and accurate data of the dogs in which infection was not reported until 2012, with the exception of large-scale treatment schemes of the dog population using praziquantel tablets, whereas unpublished data based on Echioncoccus coproantigen ELISA tests (fecal antigen detection) for 


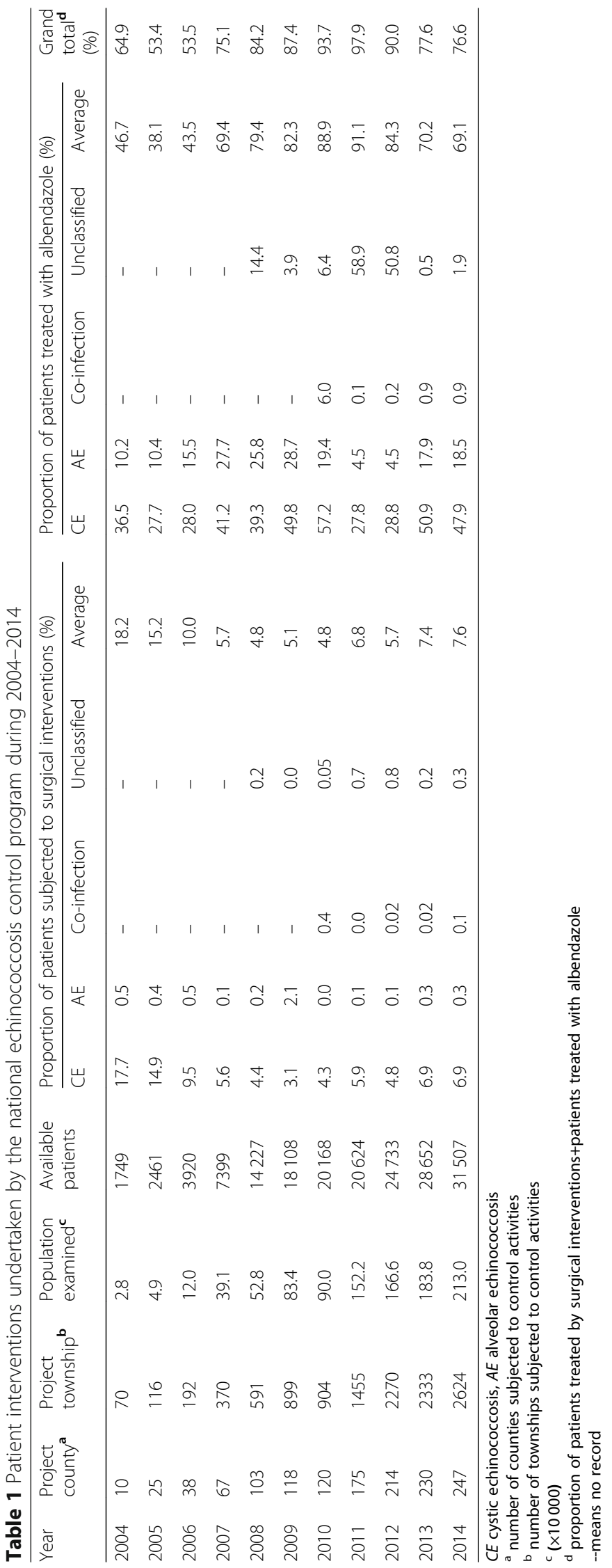


Table 2 Patient interventions at different administrative levels in the areas endemic for echinococcosis during the period 2008-2014

\begin{tabular}{|c|c|c|c|c|c|c|c|c|}
\hline \multirow[t]{3}{*}{ Types } & \multicolumn{8}{|c|}{ Mean prevalence (per $10^{5}$ population) } \\
\hline & \multicolumn{4}{|c|}{$\begin{array}{l}\text { Patients subjected to surgery } \\
\text { (Number of cases) }\end{array}$} & \multirow[t]{2}{*}{ Case } & \multirow[t]{2}{*}{$\begin{array}{l}\text { Proportion } \\
(\%)\end{array}$} & \multicolumn{2}{|c|}{$\begin{array}{l}\text { Patients treated with albendazole } \\
\text { (Number of person-hours) }\end{array}$} \\
\hline & Case & $\begin{array}{l}\text { Proportion } \\
(\%)\end{array}$ & $\begin{array}{l}\text { County level } \\
(95 \% \mathrm{Cl})\end{array}$ & $\begin{array}{l}\text { Township level } \\
(\mathbf{9 5 \%} \mathbf{C l})\end{array}$ & & & $\begin{array}{l}\text { County level } \\
(95 \% \mathrm{Cl})\end{array}$ & $\begin{array}{l}\text { Township level } \\
(\mathbf{9 5 \%} \mathbf{C l})\end{array}$ \\
\hline CE & 10053 & 88.4 & $2.71(1.32-4.11)$ & $2.94(1.50-4.49)$ & 74145 & 55.2 & $10.23(4.85-15.61)$ & $21.79(9.44-31.43)$ \\
\hline $\mathrm{AE}$ & 685 & 6.0 & $0.11(0-0.24)$ & $0.21(0-0.46)$ & 28833 & 21.5 & $3.93(1.75-6.09)$ & $8.52(3.51-13.52)$ \\
\hline Co-infection ${ }^{a}$ & 513 & 4.5 & $0.02(0-0.06)$ & $0.04(0-0.09)$ & 29469 & 22.0 & $0.25(0-0.63)$ & $0.56(0-1.40)$ \\
\hline Unclassified $^{b}$ & 121 & 1.1 & $0.07(0-0.15)$ & $0.1(0.01-0.3)$ & 1802 & 1.3 & $4.36(0-9.75)$ & $7.41(0-16.08)$ \\
\hline
\end{tabular}

${ }^{\mathrm{a}}$ statistics from 2010 to $2014 .^{\mathrm{b}}$ statistics from 2008 to 2014. Person-hours: the total times after treatment for patients (surgical cases included)

$C E$ cystic echinococcosis, $A E$ alveolar echinococcosis

the average dog infection rates (available via the national pilot surveillance system) ranged between $2.89 \%$ (15317/ 530 135) in 2013 and $3.35 \%(3944 / 117$ 671) in 2014 in the endemic areas.

\section{Economics analysis}

Over the 10-year period, a total costs of USD 110.7 million after discount was estimated for the national program by the National Ministry of Health, a sum that was verified by the health administration departments of the endemic areas. The direct total costs, ranging from albendazole treatment and surgical operations to deworming the dog population with oral praziquantel, were calculated at USD 12.3 million for humans and USD 15.8 million for dogs after discount by sum from 2004 to 2014 respectively. This means that in 2014, compared to 2006, the annual and accumulated intervention costs with respect to humans and dogs had increased 2840 times and 21.8 times, respectively. The annual cost proportion increased by $190 \%$ ([31.58-10.88]/10.88) and the accumulated costs proportion increased by $187 \%([24.42-8.51] / 8.51)$ in comparison to 2006, respectively (Table 4).

\section{Estimated gaps}

Although the current financial inputs did not fully adapt to the emerging number of patients and dogs in need of treatment and deworming, the gap narrowed by $68 \%$ in 2014, while it narrowed by $66 \%$ with respect to the accumulated costs in comparison to 2006, which is in accordance with the annual increases by China's Central Government (Table 5).

\section{Discussion}

Echinococcosis transmission mainly occurs in the pastoral and farming-pastoral regions of western China due to the complex animal populations and Echinococcus spp., which involve a wide range of intermediate and definitive hosts. Human epidemiological surveys may be

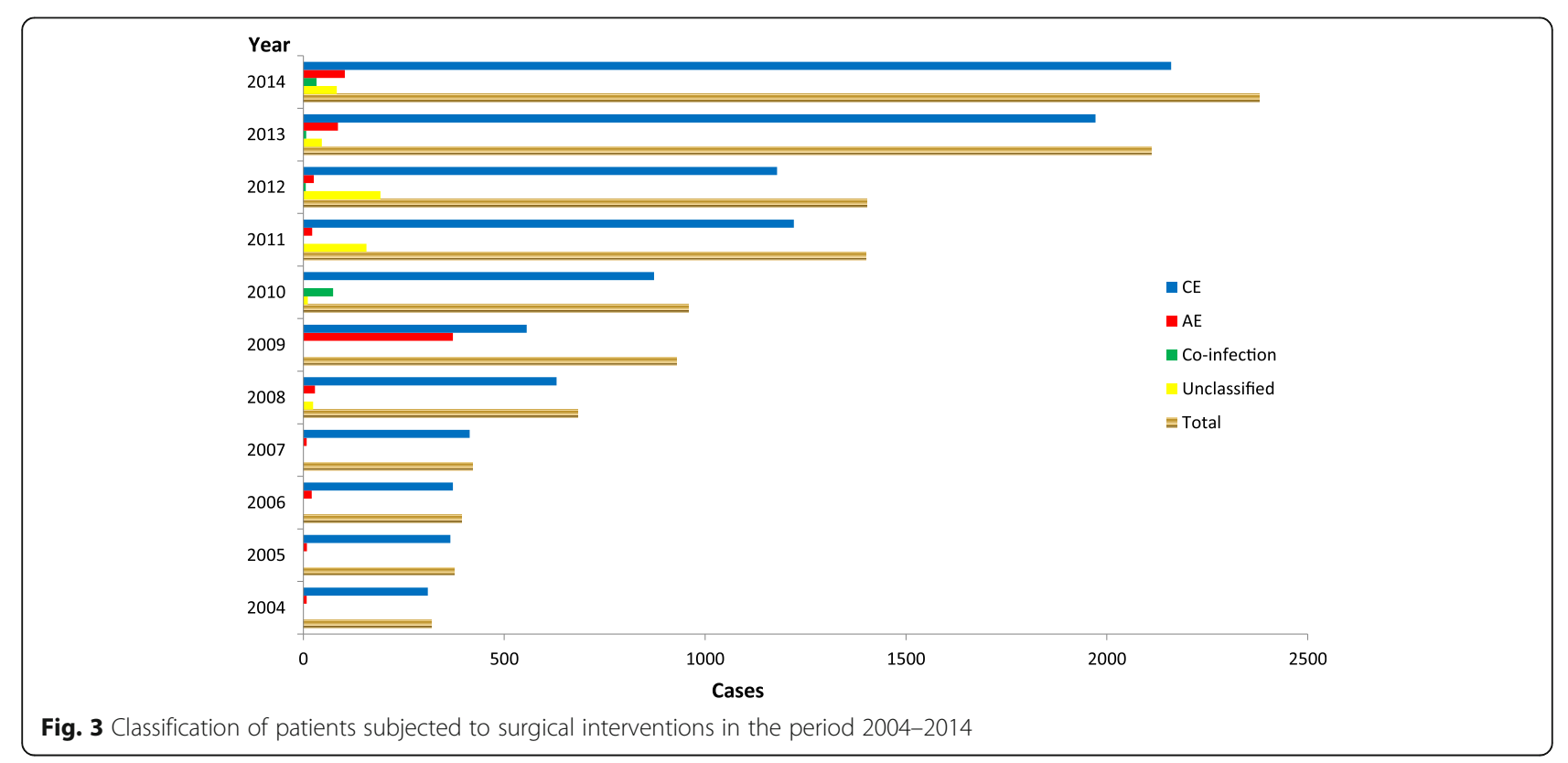




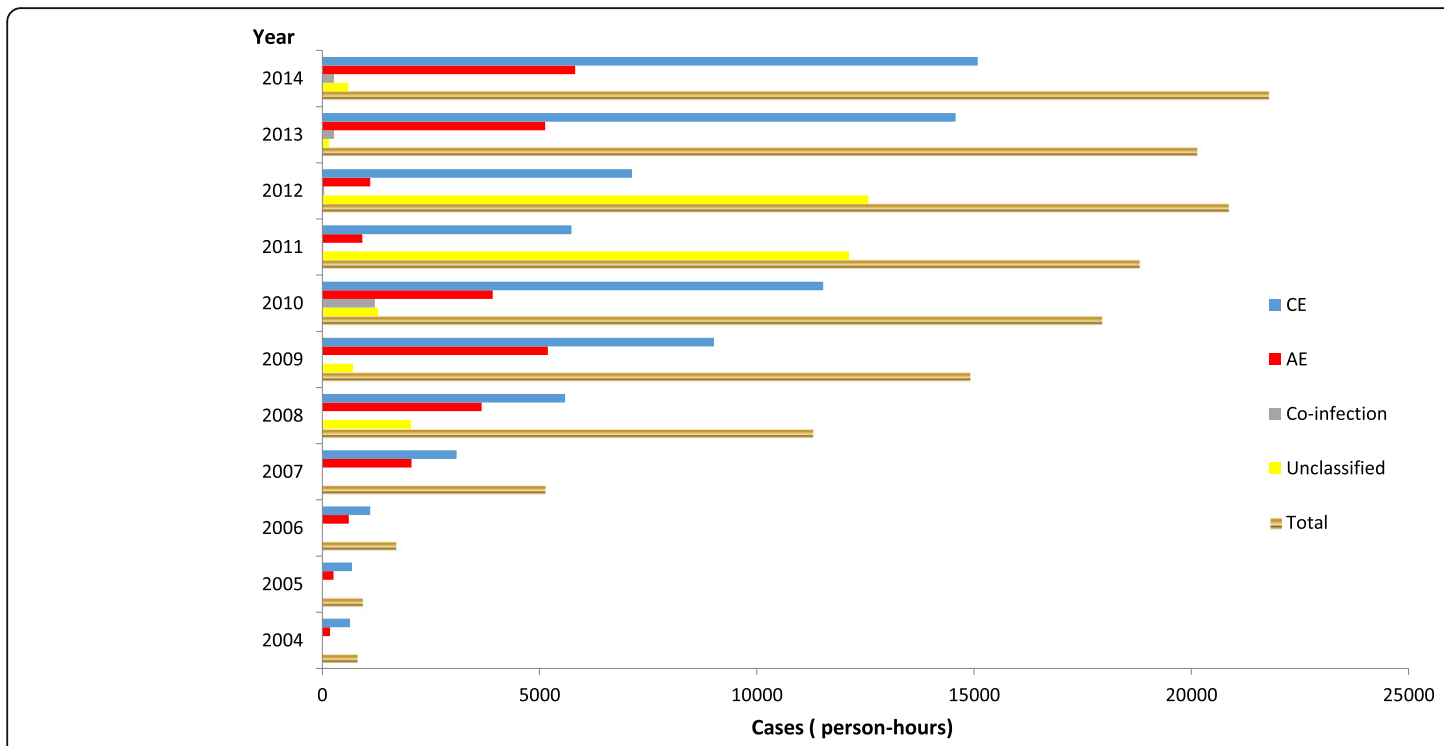

Fig. 4 Classification of patients receiving albendazole treatment in the period 2004-2014

carried out by serology, and ultrasonography is regarded as a simple, safe and reliable diagnostic tool for screening for internal cysts. Importantly, relatively safe and effective chemotherapy is available [20-29].

The data in this study demonstrate that the grand total person-hours spent on surgical interventions and treatment (including postoperative treatment) was $76.6 \%$ of the corresponding grand total proportion for the year of 2014, which was 1.2-fold compared to 2005. These results show a high disease burden in terms of DALYs in the endemic areas, which indicates that echinococcosis is a serious threat in parts of China. However, with the large-scale population screening, the patient numbers increased 18-fold in 2014 compared to 2004, while the prevalence per 100000 population rate increased 17 -fold at the county level and 10.8 times at the township level during the same time. Moreover, 1.5 times as many new cases were found, and the cumulative cases (expressed in person-hours) for surgical operations increased 4.2 times, which was 3.8 times the value for $\mathrm{CE}$ and 8.1 times the value for AE. For treatment (expressed in person-hours), the cumulative cases increased 5.7 times the value for the $\mathrm{CE}$ cases and 3.3 times the value for the AE cases for the last 5 years (2009-2014) compared to the former 5 years (2004-2008). In addition, increases of 0.6 times co-infection with surgical interventions and 0.5 times the co-infection cases with treatment for the last 3 years (2012-2014) were sustained compared to the

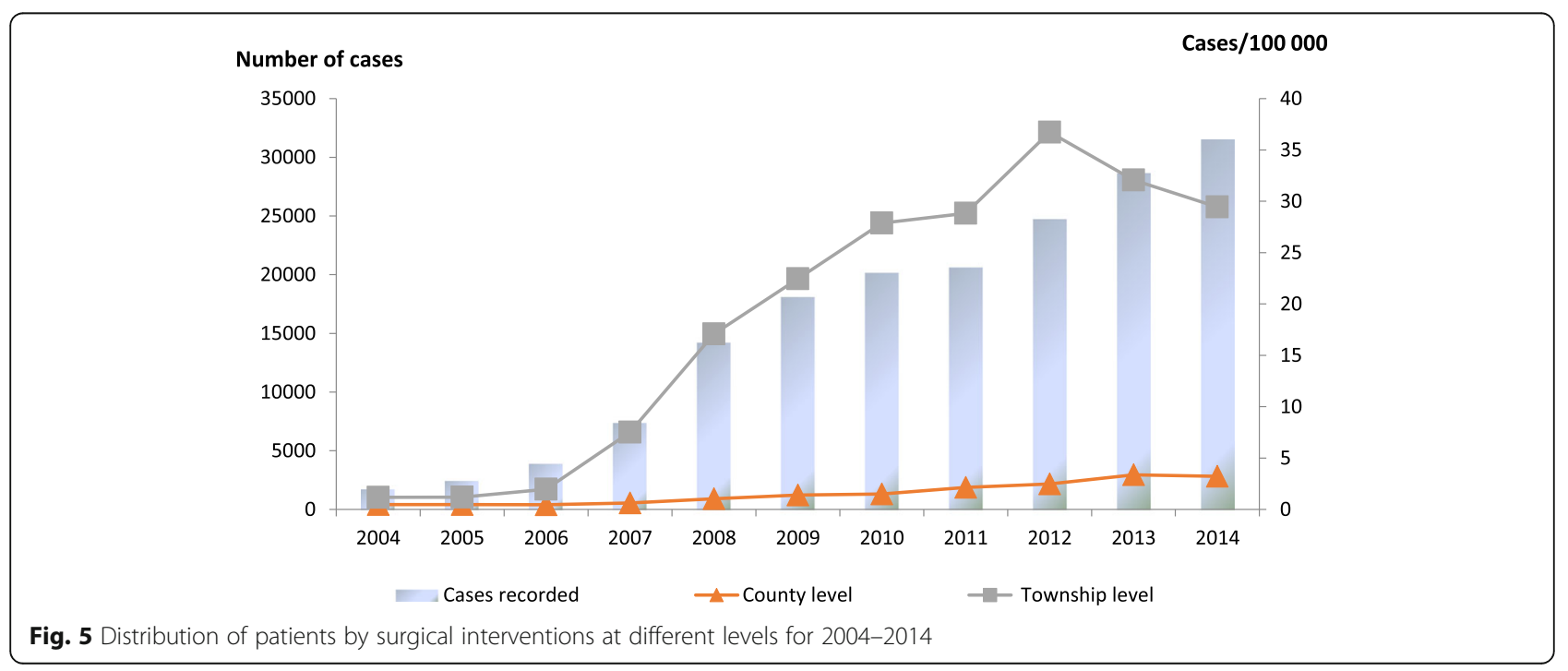




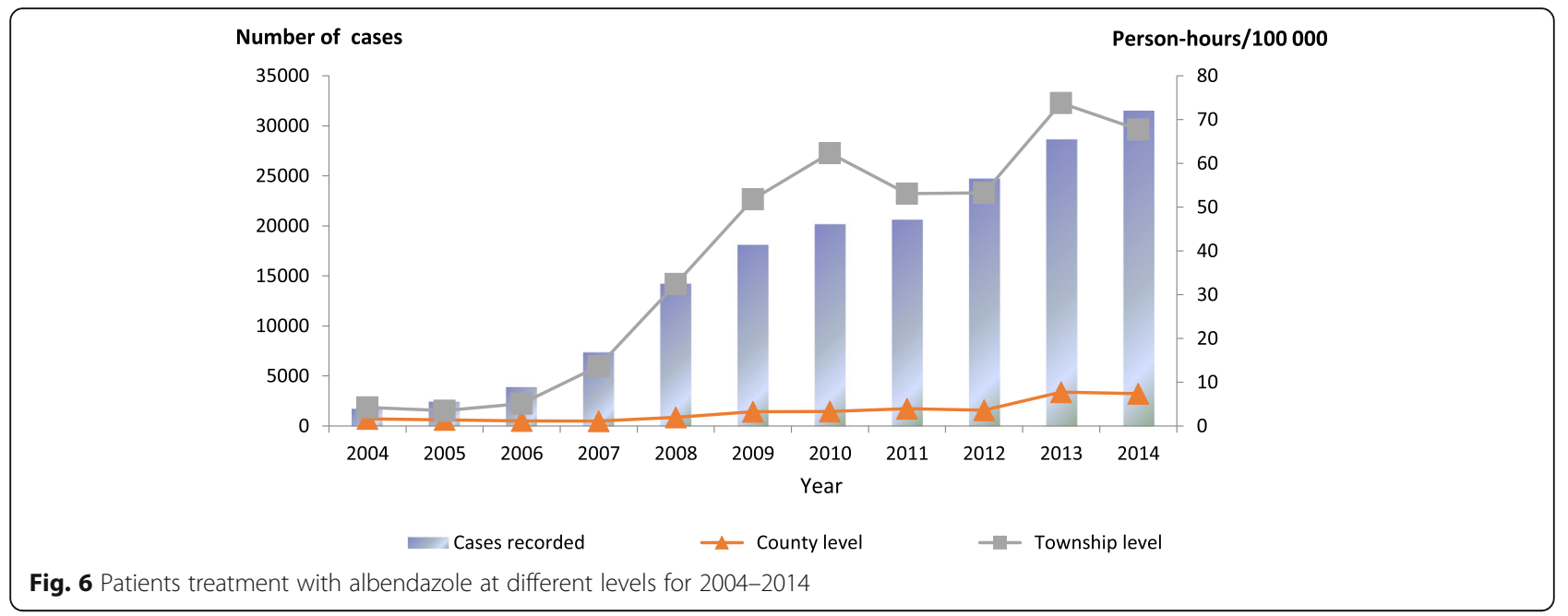

former 2 years (2010-2011). For the unclassified cases, the cumulative cases were 13.7 times the value obtained with respect to surgical interventions and 6.3 times the value obtained for treatment for the last 4 years (20112014) compared to the former 3 years (2008-2010).

According to the mean prevalence rate at the county and township level, more diagnosed patients will be reported with a higher prevalence following a large-scale population screening; however, the characteristics of the co-infection cases and the unclassified cases treated during an additional 3-year period decreased by onehalf. The results indicate that patients with co-infection and unclassified cases display an annual decreasing trend. Moreover, the patient treatments varied widely due to improvement of the diagnostic accuracy through ultrasound screening for the entire exposed population in high-risk areas. Therefore, patient diagnosis and management, including surgery and treatment with albendazole in endemic areas, are sustainable, whereas established surveillance systems for population prevalence and relevant factors need improvement at different levels, including compliance with respect to albendazole treatment, clinical follow-up, personal information and timely treatment updates of record.

Dogs are definitive hosts in the semi-domestic life cycle of E. multilocularis and play a key role due to their close association with E. granulosus throughout parasite transmission in the endemic areas of western China [11, 13, 30, 31]. Since 2005, the echinococcosis control initiative in China provides complete data for the management of registered dogs including deworming of infected dogs. Over the 7-year period of 20052011, the number of registered dogs increased 9-fold, but the deworming coverage rate only increased 8-fold in 2011 compared to the rate in 2005 . However, according to the complete data records of registered dogs

Table 3 The situations for registered dogs deworming by the national echinococcosis control program from 2004 to 2014

\begin{tabular}{|c|c|c|c|c|}
\hline Year & $\begin{array}{l}\text { Registered dogs } \\
(\times 10000)\end{array}$ & $\begin{array}{l}\text { Deworming cases } \\
(\times 10000)\end{array}$ & $\begin{array}{l}\text { Coverage rate } \\
(\%)\end{array}$ & $\begin{array}{l}\text { Single deworming } \\
(\times 10000)\end{array}$ \\
\hline 2004 & 9.6 & 3.7 & 38.2 & - \\
\hline 2005 & 23 & 2.4 & 10.2 & - \\
\hline 2006 & 76.2 & 7.9 & 10.4 & - \\
\hline 2007 & 93.2 & 38.9 & 41.5 & - \\
\hline 2008 & 109.5 & 44.5 & 40.7 & - \\
\hline 2009 & 115 & 46.8 & 40.7 & - \\
\hline 2010 & 203.3 & 118.9 & 58.5 & - \\
\hline 2011 & 216 & 176.9 & 81.9 & - \\
\hline 2012 & 325.6 & $240.5^{a}$ & 73.9 & 1332.00 \\
\hline 2013 & 263.1 & $170.3^{a}$ & 64.7 & 1714.20 \\
\hline 2014 & 269 & $178.0^{\mathrm{a}}$ & 66.2 & 2304.50 \\
\hline
\end{tabular}

${ }^{a}$ Based on statistical estimation. Coverage rate $=$ deworming cases/registered dogs 
Table 4 Analysis of input-cost at the national level for patient and dog interventions from 2004 to 2014

\begin{tabular}{|c|c|c|c|c|c|c|c|c|}
\hline \multicolumn{3}{|c|}{ Total input } & \multicolumn{4}{|c|}{ Cost for patient and dog interventions } & \multicolumn{2}{|c|}{ Proportion (\%) } \\
\hline Year & Annual & Accumulated & Patients & Dogs & Annual & Accumulated & Annual & Accumulated \\
\hline 2004 & - & - & - & - & - & - & - & - \\
\hline 2005 & 30.1 & 30.1 & - & - & - & - & - & - \\
\hline 2006 & 108.2 & 138.3 & 0.1 & 11.7 & 11.8 & 11.8 & 10.9 & 8.5 \\
\hline 2007 & 392.3 & 530.6 & 51.0 & 55.6 & 106.6 & 118.3 & 27.2 & 22.3 \\
\hline 2008 & 1038.4 & 1569.0 & 82.3 & 63.7 & 146.0 & 264.3 & 14.1 & 16.9 \\
\hline 2009 & 1119.9 & 2688.9 & 112.5 & 67.6 & 180.01 & 444.9 & 16.1 & 16.5 \\
\hline 2010 & 1709.3 & 4398.1 & 115.6 & 171.3 & 286.9 & 731.2 & 16.8 & 16.6 \\
\hline 2011 & 1683.0 & 6081.1 & 168.2 & 254.3 & 422.6 & 1153.8 & 25.1 & 19.0 \\
\hline 2012 & 1571.0 & 7652.1 & 168.7 & 346.2 & 515.0 & 1668.8 & 32.8 & 21.9 \\
\hline 2013 & 1710.1 & 9362.2 & 252.0 & 243.6 & 495.6 & 2164.4 & 29.0 & 23.1 \\
\hline 2014 & 1705.6 & 11067.9 & 284.0 & 254.7 & 538.7 & 2703.1 & 31.6 & 24.4 \\
\hline
\end{tabular}

State inputs and costs are expressed in USD 10 000. --means no data

from 2012 to 2014, the coverage rate remained near $70 \%$ and exhibited an estimated 7-fold increase compared to 2005. These results were similar to those of the 2012-2014 period. Additionally, monthly anthelmintic treatment for dogs was more effective compared to previous studies [32,33]. Data for the annual number of dogs deworming with dog-time calculated for large-scale deworming for the registered dogs increased 1.7-time in 2014 compared to 2012 and was estimated at 12 times per dog per year for 2014. In conclusion, the estimation of dog management and treatment over this period was performed at completely different levels on an annual timeline and helped reduce the parasite load to control the disease.

Notably, a strong relationship exists between patients and dogs, which means that there is a high risk that humans ingest parasite eggs directly through contact with infectious dogs or indirectly from contaminated environments. Studies also reveal that E. granulosus eggs remain viable and infective after 41 months that include warm summer and cold winter conditions $[1,2,12,13]$. We also found that a positive correlation $(R=0.97, P<$ 0.01 ) between registered dogs with the available patients after Spearman's correlation analysis of the present data. Currently, the management of stray dogs is particularly difficult in some regions where cultural acceptance is prevalent, several studies indicate that distribution of anthelmintic baits against wild and stray definitive hosts results in significant reductions in AE prevalence, particularly if innovative bait delivery is used [13, 34-37]. According to WHO reports regarding endemic regions, the human prevalence rates for $\mathrm{CE}$ can reach more than 50 per 100000 person-years with prevalence levels as high as $5-10 \%$ worldwide; similar rates have been reported in regions of western China [1, 6, 17, 38, 39].

The national echinococcosis control program demonstrates that mass human population screening of echinococcosis, early detection and prompt treatment of human cases and large-scale dog deworming are valuable (particularly with respect to coverage) based on the

Table 5 Input gap by estimation for patient and dog interventions during 2006-2014

\begin{tabular}{|c|c|c|c|c|c|c|}
\hline \multirow[t]{2}{*}{ Year } & \multicolumn{2}{|c|}{ Input gap for patients } & \multicolumn{2}{|c|}{ Input gap for dogs } & \multicolumn{2}{|c|}{ Grand total proportion (\%) } \\
\hline & Annual & Accumulated & Annual & Accumulated & Annual & Accumulated \\
\hline 2006 & 0.3 & 0.3 & 100.8 & 100.8 & 90.0 & 90.0 \\
\hline 2007 & 16.8 & 17.1 & 77.6 & 178.5 & 47.0 & 62.3 \\
\hline 2008 & 17.0 & 34.1 & 92.9 & 271.4 & 43.0 & 53.6 \\
\hline 2009 & 17.0 & 51.1 & 98.5 & 369.9 & 39.1 & 48.5 \\
\hline 2010 & 9.3 & 60.4 & 121.6 & 491.5 & 31.3 & 43.0 \\
\hline 2011 & 5.7 & 66.1 & 56.2 & 547.7 & 12.8 & 34.7 \\
\hline 2012 & 20.0 & 86.1 & 122.4 & 670.1 & 21.7 & 31.3 \\
\hline 2013 & 75.4 & 161.5 & 132.8 & 802.9 & 29.6 & 30.8 \\
\hline 2014 & 89.4 & 250.9 & 130.1 & 933.0 & 29.0 & 30.5 \\
\hline
\end{tabular}

Inputs are expressed in USD 10000 
cost proportion changes, with the exception of limitations of minor values based on the estimation. The results of the simple cost analysis show that over the 10 -year period, a total cost of USD 27.0 million after discount on patients' treatment and registered dogs deworming was accumulated. It reached $24.4 \%$ accounting for $1 / 4$ of the total financial input, though currently they have not adapted to the emerging numbers of patients in need of treatment and dogs that should be dewormed. The annual and the accumulated costs increased 57-fold and 368-fold compared to those in 2005 respectively, and the grand total proportion narrowed by $70 \%$ with respect to annual or accumulated gaps, which is in accordance with the annual increase of the cost for patients and anti-parasite treatment of registered dogs.

In this study, due to the limitation of data confidentiality, we only collected data approved by the National Ministry of Health up to 2014, so the 4 years data after that were not covered and unable to include the distribution of wild canines (stray dogs and etc.) through the national program, which is a critical for blocking parasitic egg transmission. Moreover, although the national control programme was led by National Ministry of Health, the livestock management and vaccination were the responsibility of the Ministry of Agriculture and the outcomes will depend on their reports. In addition, the national surveillance system for echinococcosis was established in 2016, as there were hardly any historical data for analysis to fully reflect the prevalence for patients and dogs, except for the two national surveys in 2004 and 2012.

All in all, based on the results obtained through this study, we recommend that it will be more effectively on the national programme evaluation by multi-sectoral joints in the future, more attention should be paid to controlling wild canines during the ongoing program period and with increased focus on patients and dog interventions by the Chinese Government.

\section{Conclusions}

This study showed that in endemic areas, patient diagnosis and management, dog management and treatment over this period helped reduce the parasite load to control the disease. Meanwile, it is suggested that more attention should be paid to controlling wild canines during the ongoing program period and sustainable follow-up evaluations by multi-sectoral joints are crucial for success and continued implementation of the national program.

\section{Abbreviations}

AE: Alveolar echinococcosis; CAAT: Cost for accumulated actual patients treatment; CAD: Cost for actual dogs deworming; CADD: Cost for accumulated actual dogs deworming; CAT: Cost for actual patient treatment;
CE: Cystic echinococcosis; DALYs: Disability-adjusted life years; WHO: World Health Organization

\section{Acknowledgements}

We would like to thank all those participants for their contribution of time and patience in the study. Our gratitude also goes to Dr. Robert Bergquist for his critical comments and revisions on the manuscript.

\section{Declarations}

The authors declare that they have no competing interests.

\section{Authors' contributions}

QY and NX designed the study and QY was the principal writer of the proposals, SH and TT did data management and quality control, X-NZ supervised the study. All authors read and approved the final manuscript.

\section{Funding}

This study was supported in part by the Program for the National Sharing Service Platform for Parasite Resources (TDRC-22), the Program for National Science and Technology Major Program (Grant No. 2012ZX10004-220) and the project of Ganzi Tibetan Autonomous Prefecture station for echinococcosis control, China CDC.

\section{Availability of data and materials}

The supporting data in this paper are included in the context.

Ethics approval and consent to participate

Not applicable as the study does not involve the use of any animal or human samples.

\section{Consent for publication \\ Agreement for publication.}

\section{Competing interests}

Xiao-Nong Zhou is an Editor-in-Chief of the journal Infectious Diseases of Poverty. He was not involved in the peer-review or handling of the manuscript.

The authors have no other competing interests to disclose.

\section{Author details}

${ }^{1}$ Department of Echinococcosis, National Institute of Parasitic Diseases, Chinese Center for Disease Control and Prevention, Shanghai 200025, China. ${ }^{2}$ Chinese Center for Tropical Diseases Research, Shanghai 200025, China. ${ }^{3}$ WHO Collaborating Centre for Tropical Diseases, Shanghai 200025, China. ${ }^{4}$ National Center for International Research on Tropical Diseases, Ministry of Science and Technology, Shanghai 200025, China. ${ }^{5}$ Key Laboratory of Parasite and Vector Biology, Ministry of Health, Shanghai 200025, China. ${ }^{6}$ National Institute of Parasitic Diseases, Chinese Center for Disease Control and Prevention, Shanghai 200025, China.

Received: 28 April 2020 Accepted: 27 August 2020

Published online: 02 October 2020

References

1. Eckert J, Schantz PM, Gasser RB, et al. Geographic distribution and incidence. In: Eckert J, Gemmell MA, Meslin FX, Pawlowski ZS, editors. WHO/ OIE manual on echinococcosis in humans and animals: a public health problem of global concern. Paris: The World Health Organization; 2001. p. 100-42.

2. McManus DP, Zhang W, Li J, Bartley PB. Echinococcosis. Lancet. 2003;362: 1295-305.

3. World Health Organization. The world health report. Geneva: World Health Organization; 2004. Available from http://www.who.int/whr/2004.

4. Torgerson PR, Keller K, Magnotta M, Ragland N. The global burden of alveolar echinococcosis. PLoS Negl Trop Dis. 2010;4(6):e722.

5. Cadavid Restrepo AM, Yang YR, McManus DP, Gray DJ, Giraudoux P, Barnes TS, Williams GM, Soares Magalhães RJ, Hamm NA, Clements AC. The landscape epidemiology of echinococcoses. Infect Dis Poverty. 2016;5:13.

6. Chai JJ. Epidemiological studies on cystic echinococcosis in China- a review. Biomed Environ Sci. 1995;8:122-36. 
7. Budke CM, Qiu J, Wang Q, Zinsstag J, Torgerson PR. Utilization of DALYs in the estimation of disease burden for a high endemic region of the Tibetan plateau. Am J Trop Med Hyg. 2004;71:56-64.

8. Budke CM, Deplazes P, Torgerson PR. Global socioeconomic impact of cystic echinococcosis. Emerg Infect Dis. 2006;12:296-303.

9. Wang G-Q. Epidemiological survey on Echinococcosis in China. Shanghai Sci Technol Press. 2016. p. 6-9.

10. Gottstein B, Saucy F, Deplazes P, Reichen J, Demierre G, Busato A, et al. Is high incidence of Echinococcus multilocularis in wild and domestic animals associated with disease incidence in humans? Emerg Infect Dis. 2001;7:408-12.

11. Kapel CMO, Torgerson PR, Thompson RCA, Deplazes P. Reproductive potential of Echinococcus multilocularis in experimentally infected foxeses, dogs, raccoon dogs and cats. IntJ Parasitol. 2006;36:79-86.

12. Craig PS. Epidemiology of human alveolar echinococcosis in China. Parasitol Int. 2006:55:S221-5.

13. Kachani M, Heath D. Dog population management for the control of human echinococcosis. Acta Trop. 2014;139:99-108.

14. Zhang W, Zhang Z, Wu W, Shi B, Li J, Zhou X, et al. Epidemiology and control of echinococcosis in Central Asia, with particular reference to the People's Republic of China. Acta Trop. 2015;141:235-43.

15. National Ministry of Health of the People's Republic of China. National Control Plan on the Prevention and Control of key parasitic Diseases (20062015). http://www.moh.gov.cn/mohbgt/pw10604/200804/27592.shtml.2006.

16. National Ministry of Health of the People's Republic of China. National action plan for the Prevention and Control of echioncoccosis (2010-2015). http://www.nhfpc.gov.cn/zwgkzt/wsbysj/201012/50041.shtml.2010.

17. Eckert J, Deplazes P. Biological, epidemiological, and clinical aspects of echinococcosis, a zoonosis of increasing concern. Clin Microbiol Rev. 2004; 17:107-25.

18. Jimenez S, Perez A, Gil H, Schantz PM, Ramalle E, Juste RA. Progress in control of cystic echinococcosis in La Rioja, Spain: decline in infection incidences in human and animal hosts and economic costs and benefits. Acta Trop. 2002;83:213-21.

19. Zhou XN, Wang LY, Chen MG, Wang TP. Guo JG etc. an economic evaluation of the national schistosomiasis control programme in China from 1992 to 2000. Acta Trop. 2005:96:255-65.

20. Carabin H, Budke CM, Cowan LD, Willingham AL III, Torgerson PR. Methods for assessing the burden of parasitic zoonoses: cysticercosis and echinococcosis. Trends Parasitol. 2005;21:327-33.

21. Wang $Q$, Huang $Y$, Huang $L$, et al. Dominique A Vuitton, Patrick Giraudoux, Philip S Craig and Weiping Wu. Review of risk factors for human echinococcosis incidence on the Qinghai-Tibet Plateau, China: a prospective for control options. Infect Dis Poverty. 2014;3:3.

22. Aoki T, Hagiwara M, Yabuki H, Ito A. Unique MRI findings for differentiation of an early stage of hepatic alveolar echinococcosis. Case Rep. 2015;2015: bcr2014208123.

23. Surgery B. CT scanning in identification of sheep cystic echinococcosis. Biomed Res Int. 2017;2017:1-6.

24. Liu H, Zhang C, Fan X, Duan Y, Xiao T, Du G, et al. Robust phase-retrievalbased $X$-ray tomography for morphological assessment of early hepatic echinococcosis infection in rats. PLoS One. 2017;12(9):e183396.

25. Osimani JJ, Migliaro EF, Abella CM. Experimental study of the effect of ultrasonics on the larva of Echinococcus granulosus (hydatid cyst). Ann Parasitol Hum Comp. 1953;28(1/2):33-46.

26. Gharbi HA, Hassine W, Brauner MW, et al. Ultrasound examination of the hydatic liver. Radiology. 1981;139(2):459-63.

27. Aubry G, Tillier H, Massonnat J, Boichard R. Vertebrocostal echinococcosis; presentation of specimen and x-ray pictures. Alger Medicale. 1952;56(10):712-9.

28. Koufakis T, Margaritis A. Right upper quadrant pain: a case where diagnosis was made from the chest X-ray. Pan Afr Med J. 2014;17(1):60.

29. Shah T, Geyt JL, Atkins J. Let sleeping dogs lie: a surprising chest $X$-ray in the paediatric emergency department. Case Rep. 2014;2014:bcr2014203973.

30. Budke CM, Campos-Ponce M, Qian W, Torgerson PR. A canine purgation study and risk factor analysis for echinococcosis in a high endemic region of the Tibetan plateau. Vet Parasitol. 2005;127:4349.

31. Xiao N, Yao JW, Ding W, Giraudoux P, Craig PS, Ito A. Priorities for research and control of cestode zoonoses in Asia. Infect Dis Poverty. 2013;2:16.

32. Budke CM, Qiu J, Wang Q, Torgerson PR. Economic effects of echinococcosis on a highly endemic region of the Tibetan plateau. Am J Trop Med Hyg. 2005;73:2-10.
33. Schantz PM, Wang H, Qiu J, et al. Echinococcosis on the Tibetan plateau: incidence and risk factors for cystic and alveolar echinococcosis in Tibetan populations in Qinghai Province, China. Parasitology. 2003;127:S109-20.

34. Morishima Y, Tsukada H, Nonaka N, Oku Y, Kamiya M. Evaluation of coproantigen diagnosis for natural Echinococcus multilocularis infection in red foxes. Jpn J Vet Res. 1999;46(4):185-9.

35. Tsukada H, Morishima Y, Nonaka N, Oku Y, Kamiya M. Preliminary study of the role of red foxes in Echinococcus multilocularis transmission in the urban area of Sapporo, Japan. Parasitology. 2000;120(Pt 4):423-8.

36. Yu Q, Xiao N, Yang SJ, Han S. Deworming of stray dogs and wild canines with praziquantel-laced baits delivered by an unmanned aerial vehicle in areas highly endemic for echinococcosis in China. Infect Dis of Poverty. 2017:6:117.

37. Otero-Abad B, Torgerson PR. A systematic review of the epidemiology of echinococcosis in domestic and wild animals. PLoS Negl Trop Dis. 2013;7(6):e2249.

38. Reuter S, Jensen B, Buttenschoen K, Kratzer W, Kern P. Benzimidazoles in the treatment of alveolar echinococcosis: a comparative study and review of the literature. J Antimicrob Chemother. 2000;46:451-6.

39. Barnes TS, Deplazes P, Gottstein B, Jenkins DE, Mathisb A, Siles-Lucasf M, et al. Challenges for diagnosis and control of cystic hydatid disease. Acta Trop. 2012;123:1-7.

\section{Ready to submit your research? Choose BMC and benefit from:}

- fast, convenient online submission

- thorough peer review by experienced researchers in your field

- rapid publication on acceptance

- support for research data, including large and complex data types

- gold Open Access which fosters wider collaboration and increased citations

- maximum visibility for your research: over $100 \mathrm{M}$ website views per year

At $\mathrm{BMC}$, research is always in progress.

Learn more biomedcentral.com/submissions 